\title{
Assessing effects of a media campaign on HIVIAIDS awareness and prevention in Nigeria: results from the VISION Project Joseph Keating*1, Dominique Meekers ${ }^{1}$ and Alfred Adewuyi ${ }^{2}$
}

\author{
Address: ${ }^{1}$ Department of International Health and Development, Tulane University School of Public Health and Tropical Medicine, 1440 Canal \\ Street, New Orleans, LA, 70112, USA and ${ }^{2}$ Centre for Research, Evaluation Resources and Development, 19 Ayeloja Street, Oke Gada Ede, Osun \\ State, Nigeria \\ Email: Joseph Keating* - jkeating@tulane.edu; Dominique Meekers - dmeekers@tulane.edu; Alfred Adewuyi - alfredadewuyi@yahoo.com \\ * Corresponding author
}

Published: 03 May 2006

BMC Public Health 2006, 6:123 doi: I0.1 I86/147|-2458-6-123

This article is available from: http://www.biomedcentral.com/147I-2458/6/123

(C) 2006 Keating et al; licensee BioMed Central Ltd.

This is an Open Access article distributed under the terms of the Creative Commons Attribution License (http://creativecommons.org/licenses/by/2.0), which permits unrestricted use, distribution, and reproduction in any medium, provided the original work is properly cited.
Received: 15 December 2005

Accepted: 03 May 2006

\begin{abstract}
Background: In response to the growing HIV epidemic in Nigeria, the U.S. Agency for International Development (USAID) initiated the VISION Project, which aimed to increase use of family planning, child survival, and HIVIAIDS services. The VISION Project used a mass-media campaign that focused on reproductive health and HIVIAIDS prevention. This paper assesses to what extent program exposure translates into increased awareness and prevention of HIVIAIDS.

Methods: This analysis is based on data from the 2002 and 2004 Nigeria (Bauchi, Enugu, and Oyo) Family Planning and Reproductive Health Surveys, which were conducted among adults living in the VISION Project areas. To correct for endogeneity, two-stage logistic regression is used to investigate the effect of program exposure on I) discussion of HIVIAIDS with a partner, 2) awareness that consistent condom use reduces HIV risk, and 3) condom use at last intercourse.

Results: Exposure to the VISION mass media campaign was high: $59 \%, 47 \%$, and $24 \%$ were exposed to at least I VISION radio, printed advertisement, or TV program about reproductive health, respectively. The differences in outcome variables between 2002 baseline data and the 2004 follow-up data were small. However, those with high program exposure were almost one and a half (Odds Ratio [O.R.] = I.47, 95\% Confidence Interval [C.I.] I.0I-2.16) times more likely than those with no exposure to have discussed HIVIAIDS with a partner. Those with high program exposure were over twice (O.R. $=2.20$, C.I. I.49-3.25) as likely as those with low exposure to know that condom use can reduce risk of HIV infection. Program exposure had no effect on condom use at last sex.
\end{abstract}

Conclusion: The VISION Project reached a large portion of the population and exposure to mass media programs about reproductive health and HIV prevention topics can help increase HIVIAIDS awareness. Programs that target rural populations, females, and unmarried individuals, and disseminate information on where to obtain condoms, are needed to reduce barriers to condom use. Improvements in HIVIAIDS prevention behaviour are likely to require that these programmatic efforts be continued, scaled up, done in conjunction with other interventions, and targeted towards individuals with specific socio-demographic characteristics. 


\section{Background}

Like many African countries, Human Immunodeficiency Virus/Acquired Immunodeficiency Syndrome (HIV/ AIDS) is a serious concern in Nigeria. By the turn of the century it was estimated that the HIV prevalence in Nigeria had exceeded 5\%, which corresponds with approximately four million infected people [1]. In 2003, the HIV prevalence had exceeded $5.4 \%$, with some estimates putting the number of infected Nigerians around 5 million [2]. The estimated annual deaths as a result of HIV/AIDS has increased from 50,000 in 1999 to over 350,000 in 2004, at enormous cost to the economic and health sectors in the country [3]. Although many Nigerians are aware that condom use can prevent HIV infection, and condoms are widely available, consistent condom use has remained relatively low over the years [4-8].

\section{The VISION Project}

In response to the HIV/AIDS epidemic in Nigeria, the U.S. Agency for International Development (USAID) mission in Nigeria initiated the VISION Project, a three-year project designed to maximize the use of family planning services, HIV/AIDS services, and child survival services in Nigeria [9-13]. The project also sought to develop models of high-impact, high-performing family planning and reproductive health $(\mathrm{FP} / \mathrm{RH})$ service-delivery networks, built on public-private partnerships, to use as models for the delivery of similar interventions elsewhere. Mass media campaigns about HIV/AIDS and the repositioning of community-based health distribution centers were two of the primary activities undertaken by the VISION Project to improve access and awareness of $\mathrm{FP} / \mathrm{RH}$ related issues and services. Training curricula and capacity-building development, and the development of training sessions for clinical trainers at university-based hospitals, were also important project activities for increasing $\mathrm{FP} / \mathrm{RH}$ awareness and service capacity.

The VISION Project was implemented by EngenderHealth in partnership with IntraHealth, Johns Hopkins University Center for Communication Programs, Population Services International, and local non-governmental organizations (NGO) working in VISION Project target areas. The project targeted 15 local government areas (LGAs) in Bauchi, Enugu and Oyo states, and was active from September 2001 through September 2004 [9-13]. The project aimed to increase the demand for and use of $\mathrm{FP} / \mathrm{RH}$ services through behavior change communication (BCC) activities and community mobilization efforts.

The VISION Project worked with local NGOs active in the selected LGAs to develop "informed clients." BCC activities aimed to increase knowledge and to empower individuals and communities to demand quality family planning, STI/HIV/AIDS, and reproductive health infor- mation and services. The project developed information and education print materials and radio public service announcements (PSA) for women with an unmet need for family planning, as well as messages aimed at men and youth that focused on male involvement and responsibility in reproductive decision-making. In collaboration with local sports clubs, the VISION Project also developed an outreach strategy primarily aimed at youth called Sports for Life to promote healthy lifestyles and spread information on family planning and HIV/AIDS prevention during football competitions.

The VISION Project media campaign also included a set of weekly radio programs in target areas to disseminate family planning, HIV/AIDS, and other reproductive health information to the general public. VISION, with its partner NGOs, organized radio discussion clubs in the VISION Project target areas and provided these clubs with radios. In addition to these activities, the VISION partners conducted several complementary mass media activities (including radio, TV, and print). For example, the Society for Family Health (SFH) implemented several radio dramas aimed at increasing awareness of HIV/AIDS, and its causes and consequences. These radio dramas included One Thing at a Time, Garin Muna Fata (Town of Hope), Odenjiji, and Abule Oloke Merin. As well, SFH implemented a television to promote safe sex that featured Nigerian soccer superstar Sunday Oliseh. A billboard campaign to increase awareness that someone who is HIV positive may not have symptoms supplemented the radio and television campaign [14].

The purpose of this paper is twofold: 1) to identify determinants of $\mathrm{FP} / \mathrm{RH}$ program exposure, and 2) to assess the effect of a $\mathrm{FP} / \mathrm{RH}$ mass media campaign on HIV/AIDS awareness and condom use in the VISION Project target areas. Specifically, this paper tests whether exposure to VISION-related mass media programs (TV, radio, and printed advertisements about $\mathrm{FP} / \mathrm{RH}$ and HIV/AIDS) had an effect on individual level willingness to discuss HIV/ AIDS (awareness), whether said programs had an effect on individual level perception about condom use for reducing the risk of HIV infection (awareness), and whether exposure to mass media programs translates into increased condom use (HIV/AIDS prevention).

\section{Methods \\ Study areas}

Data were collected from a representative sample of households in the 15 Local Government Areas (LGA) targeted by the VISION Project. These include 5 LGAs in each of 3 states: Bauchi State located in the North-East, which is comprised mainly of Gerawa, Ningawa, Hausa, Fulani, and the Tangale ethnic groups; Eungu State located in the East, which is comprised mainly of the Igbo ethnic group; 
and Oyo State located in the South-Western part of Nigeria, which is comprised mainly of the Yoruba ethnic group. The selected LGAs in each of the 3 states represent VISION Project areas. LGAs were considered for selection into the VISION Project if: 1) the population was over $100,000,2)$ the population contained at least 20,000 women of reproductive age, 3 ) the LGA contained private and public health facilities at the primary and secondary levels, 4) the LGA has access to media resources such as radio, television and newspapers, and 5) the LGA has support from Nigeria's federal Ministry of Health $(\mathrm{MOH})$ and the relevant state-level Ministry of Health (MOH). VISION partners visited the LGAs and made the selections [10].

\section{Data}

This paper analyses data from the 2002 and 2004 household survey waves of the VISION Project evaluation $[10,13]$. The surveys were implemented by the Center for Research, Evaluation, and Resource Development (CRERD). The Tulane University Institutional Review Board approved this study. A two-stage cluster design was used to obtain a probability sample of respondents for this study. Sample size calculations were based on National contraception prevalence rates of $16 \%$ for females and $27 \%$ for males, and a design effect of 2 . The target sample size was 1,100 respondents per state (after adding $10 \%$ for potential non-response and incomplete questionnaires). This sample size will enable us to detect a change of 10 percentage points in a variety of key indicators in the VISION Project areas in each state with 90\% power and a probability of committing a type-I error set at $5 \%$ (two-sided test). In each state's VISION project area, 40 enumeration areas (EA) were randomly selected with probability of selection proportional to the population size (PPS) of the selected LGA. The State Office of the National Population Commission (NPC) provided a list of EAs in the project LGAs of each state. Within each selected EA, a household enumeration exercise was completed; between 27 and 28 households were then selected using systematic random sampling. All adults aged 15-49 years old in the household were listed, and one eligible person per household was selected using a table of random numbers. Interviewers obtained verbal informed consent from the selected participants. A total of 3,279 respondents across all three states completed the questionnaire ( $\cong 1 \%$ refusal/non-response rate) in 2004 .

Data collection was conducted by trained interviewers. All fieldwork supervisors first participated in a 5-day centralized training. Subsequent to this, supervisors and interviewers jointly participated in 5-day regional trainings. The household questionnaire was field tested prior to the onset of the survey to check for errors, and to evaluate the readiness of the interviewers.
The survey questionnaire was based on the Demographic and Health Survey questionnaire. In addition to standard demographic and fertility questions, questions related to family planning, sexual activity and behavior, and exposure to various media campaigns were also asked. Specifically, respondents were asked if they had listened to the following programs on the radio: Kusaurara, Dunniya J'atau, A New Dawn (Ayedotun), One thing At A Time, Gari Muna Fati, Abule Olokemerin, or Odenjinjin. Respondents were also asked if they had seen the Femi Kuti or Fati Mohammed television campaigns, if they had seen any HIV/AIDS or reproductive health advertisements in the newspaper, or had received any information from clinics or community health workers about HIV/AIDS or reproductive health.

The outcome measures for this analysis are as follows: 1) Have you ever talked with a partner about ways to prevent getting the virus that causes AIDS (yes/no)? 2) Can people reduce their chances of getting the AIDS virus by using a condom every time they have sex (yes/no)? 3) Did you use a condom during your last sexual encounter (yes/no)?

The respondent's age (continuous variable), education (categorized as none, primary, or secondary), religion (categorized as catholic, protestant or other Christian denomination, Muslim, or traditionalist), gender, marital status, place of residence (dichotomized as urban and peri-urban, or rural), knowledge of a condom source (yes/ no), state of residence (categorized as Bauchi, Enugu, or Oyo), and whether or not the respondent has had at least 1 partner in the past 12 months, served as control variables in all regression models (described below). Based on the distribution of the data during preliminary analyses, exposure to media was measured by dichotomizing whether a respondent reads the newspaper at least once a week (yes/no), watches television at least once a week (yes/no), or listens to the radio at least once a week (yes/ no). Media exposure variables served as control variables in the first-stage Poisson regression models only (see below).

Our indicators of program exposure included a total count of the number of $\mathrm{FP} / \mathrm{RH}$ radio programs heard, television programs seen, or printed $\mathrm{FP} / \mathrm{RH}$ advertisements seen over the past 6 months $(0-10)$. A separate count of the number of radio programs exposed to $(0-7)$, and the number of TV programs exposed to $(0-2)$, were also used as indicators of program exposure in separate models. All values, whether part of the cumulative number of programs exposed to or the individual programs exposed to for the respective media types, were then categorized as low (none), medium (one), or high (2 or more). The decision to use the same categories for each program exposure model was based on the distribution of program exposure 
Table I: Respondent characteristics by State

\begin{tabular}{|c|c|c|c|c|}
\hline & Oyo $(n=1,083)$ & Bauchi $(n=1,096)$ & Enugu $(n=1,100)$ & All* $(n=3,279)$ \\
\hline & \multicolumn{4}{|c|}{ \# (S.E.) } \\
\hline Mean age of respondents & $29.6(0.28 I)$ & $27.2(0.28)$ & $28.0(0.282)$ & $28.1(0.165)$ \\
\hline Mean number of sexual partners in past year & $\begin{array}{l}\text { I.2(0.026) } \\
\%(\text { S.E. })\end{array}$ & $1.2(0.041)$ & I.I $(0.252)$ & $1.2(0.021)$ \\
\hline $\begin{array}{l}\text { Proportion of respondents that are married or } \\
\text { living with partner }\end{array}$ & $59.7(0.015)$ & $72.8(0.013)$ & $44.9(0.015)$ & $60.1(0.009)$ \\
\hline $\begin{array}{l}\text { Proportion of respondents that know where to } \\
\text { get condoms }\end{array}$ & $57.1(0.015)$ & $25.8(0.013)$ & $51.2(0.015)$ & $42.8(0.009)$ \\
\hline \multicolumn{5}{|l|}{ Religion of household respondents } \\
\hline Catholic & $3.7(0.006)$ & $2.0(0.004)$ & $70.9(0.139)$ & $24.4(0.008)$ \\
\hline Muslim & $41.5(0.015)$ & $88.6(0.000)$ & $0.8(0.003)$ & $47.3(0.009)$ \\
\hline Protestant/other Christians & $54.5(0.015)$ & $9.0(0.009)$ & $25.8(0.013)$ & $27.1(0.008)$ \\
\hline Traditional/other & $0.4(0.002)$ & $0.4(0.002)$ & $2.5(0.005)$ & I.I (0.002) \\
\hline \multicolumn{5}{|l|}{ Location of household } \\
\hline Urban/Peri-urban & $74.2(0.013)$ & $34.9(0.014)$ & $35.5(0.014)$ & $46.2(0.009)$ \\
\hline Rural & $25.8(0.013)$ & $65.1(0.014)$ & $64.5(0.014)$ & $53.8(0.009)$ \\
\hline \multicolumn{5}{|l|}{ Gender of respondent } \\
\hline Male & $42.9(0.015)$ & $49.5(0.015)$ & $36.5(0.015)$ & $43.5(0.009)$ \\
\hline Female & $57.1(0.015)$ & $50.5(0.015)$ & $63.5(0.015)$ & $56.5(0.009)$ \\
\hline \multicolumn{5}{|l|}{ Education of respondent } \\
\hline None & $21.2(0.013)$ & $59.4(0.015)$ & $12.2(0.000)$ & $33.6(0.009)$ \\
\hline Primary & $20.2(0.012)$ & $20.3(0.012)$ & $28.4(0.136)$ & $22.9(0.007)$ \\
\hline Secondary or higher & $57.9(0.015)$ & $20.4(0.012)$ & $59.5(0.015)$ & $43.6(0.009)$ \\
\hline
\end{tabular}

*Aggregated parameter estimates across States were calculated using weighted data

data for each media type. These analyses showed that the proportion of respondents exposed to each category (i.e. low, medium, high) of program exposure was similar between total program exposure counts, radio program exposure counts only, and TV program exposure counts only. No model was run for the printed advertisement media, as the questionnaire only asked about exposure to any printed advertisement (yes/no).

\section{Data analysis}

Data analyses were done using STATA ${ }^{\mathrm{TM}}$ 7.0. Comparisons of the outcome variables were made between the baseline 2002 data and the follow-up 2004 data. Chi-square statistics and two-stage logistic regression models were used to analyze the data [15]. Using data from the 2004 follow-on survey, the Durbin-Wu-Hausman test (augmented regression test) was performed to test for endogeneity between media exposure and the respective outcomes [16]. Since the results showed evidence of endogeneity (i.e. value of one independent variable is dependent on the value of other predictor variables), two-stage logistic regressions were performed using instrumental variables of program exposure. At the first stage, Poisson regression was used to estimate the total number of exposures to VISION programs using a set of exogenous variables. Because estimated exposure is a continuous variable, respondents were recoded has having low estimated exposure if the estimated exposure was less than 1 , medium if estimated exposure was between 1 and 2, and high if estimated exposure was two or more, and used as indicators of program effectiveness in all logistic regressions. Wald statistics and log-likelihood ratios were used to identify variable significance and model fit, with alpha set at 0.05 . To control for the effect of clustering within enumeration areas (EA), the Huber-White-Sandwich estimator of variance was used to obtain empirically estimated standard errors, with the EA defined as the cluster. Standardized state-level probability weights, based on the relative population size of program LGAs in each State (pweight) were applied to regressions, and to all between state estimates.

\section{Results}

Socio-demographic characteristics of the population are presented in Table 1. The average age (28.1) of the respondents and the mean number of sexual partners in the past year (1.2) were similar across states. In Bauchi, $73 \%$ of the respondents were married; $45 \%$ reported being married in Enugu and 60\% reported being married in Oyo. Seventy-four percent of respondents in Oyo reported living in urban or peri-urban areas; $35 \%$ of respondents in Bauchi and 36\% of respondents in Enugu reported living in urban or peri-urban areas. The states also differed in educational attainment, with Bauchi reporting the lowest proportion of respondents reporting secondary or higher education (20.4\%) and Enugu reporting the highest proportion of respondents reporting secondary or higher education $(60 \%)$. Oyo had the highest proportion of Protestants/other Christians (55\%), Bauchi 
had the highest number of Muslims (89\%), and Enugu had the highest proportion of Catholics (71\%). Knowledge of a condom source also varied by state, with $57 \%$ of respondents in Oyo, and 51\% and 26\% of respondents in Enugu and Bauchi, respectively, reporting that they know where to get condoms.

\section{Exposure to media programs by the VISION partners}

Figure 1 illustrates the percentage of respondents exposed to the various VISION media programs by gender. In general, more males were exposed to programs than females, although more females were exposed to clinic-based information. VISION program exposure statistics are presented in Table 2 . The mean number of radio program exposures was highest in Bauchi (1.38) and lowest in Enugu (0.65). Bauchi also reported the highest mean number of TV program exposures (0.36). Seventy-seven percent of all respondents reported listening to the radio at least once a week and $47 \%$ reported watching TV at least once a week. On average, 59\% of respondents heard at least $1 \mathrm{FP} / \mathrm{RH}$ radio program in the past 6 months, and $24 \%$ saw a FP/RH TV program. Forty-seven percent were exposed to at least 1 advertisement about HIV/AIDS, sexual abstinence or condom use in the last 6 months. Over $96 \%$ of all respondents thought it was acceptable to discuss HIV/AIDS on TV, the radio, or in the newspaper.

Table 3 presents the results of the first stage Poisson regressions. The socio-demographic variables included were almost all significantly related to the total number of program exposures, as well as the number of radio and TV program exposures, respectively. Male respondents were more likely to be exposed to media programs than female respondents, as indicated by a positive beta coefficient, and secondary education was positively associated with the number of programs exposures; low education level was negatively associated with the number of program exposures. Respondents located in urban and peri-urban areas were also more likely to have been exposed to programs than those located in rural areas. Because socioeconomic data were not available, it is difficult to capture whether location is also serving as a proxy for wealth or access to resources. No significant relationship was detected between whether the respondent has been sexually active in past year and the number of program exposures. As expected, significant positive relationships exist between whether respondents watch TV, read the newspaper, or listen to the radio, and the number of program exposures.

\section{Effect of program exposure on HIVIAIDS awareness, perception, and prevention behaviour}

Figures 2, 3, 4 illustrate the outcome measures used in this analysis (2004 data), relative to the 2002 baseline data. The percentage of respondents that used a condom at last sex increased in all 3 states (Figure 2). Overall, the percentage increased from $13.9 \%$ in 2002 to $15.8 \%$ in 2004 , although this increase was not statistically significant $\left(\chi^{2}\right.$

Table 2: Characteristics of VISION media program exposure among respondents by State

\begin{tabular}{|c|c|c|c|c|}
\hline & Oyo $(n=1,083)$ & Bauchi $(n=1,096)$ & Enugu $(n=1,100)$ & All* $(n=3,279)$ \\
\hline & \multicolumn{4}{|c|}{ \# (S.E.) } \\
\hline Mean number of VISION radio programs exposed to & $0.91(0.026)$ & $1.38(0.039)$ & $0.65(0.025)$ & I.01 (0.020) \\
\hline \multirow[t]{2}{*}{ Mean number of VISION TV programs exposed to } & $0.32(0.018)$ & $0.36(0.019)$ & $0.19(0.013)$ & $0.29(0.010)$ \\
\hline & \multicolumn{4}{|c|}{ \% (S.E.) } \\
\hline $\begin{array}{l}\text { Percentage of respondents that read the newspaper at } \\
\text { least once a week }\end{array}$ & $32.1(0.014)$ & $14.6(0.011)$ & $30.9(0.014)$ & $24.8(0.008)$ \\
\hline $\begin{array}{l}\text { Percentage of respondents that listen to the radio at least } \\
\text { once a week }\end{array}$ & $84.2(0.011)$ & $72.2(0.014)$ & $75.5(0.013)$ & $76.6(0.008)$ \\
\hline $\begin{array}{l}\text { Percentage of respondents that watch TV at least once a } \\
\text { week }\end{array}$ & $64.9(0.015)$ & $28.5(0.014)$ & $54.4(0.015)$ & $47.1(0.009)$ \\
\hline $\begin{array}{l}\text { Percentage of respondents that heard a program } \\
\text { reproductive health message on the radio in last } 6 \\
\text { months }\end{array}$ & $63.5(0.015)$ & $62.9(0.015)$ & $50.6(0.015)$ & $59.1(0.009)$ \\
\hline $\begin{array}{l}\text { Percentage of respondents that saw a reproductive health } \\
\text { program on the TV in last } 6 \text { months }\end{array}$ & $25.0(0.013)$ & $28.5(0.014)$ & $17.0(0.011)$ & $23.8(0.008)$ \\
\hline $\begin{array}{l}\text { Percentage respondents that saw any printed } \\
\text { advertisements about HIVIAIDS, sexual abstinence, or } \\
\text { condom use in last } 6 \text { months }\end{array}$ & $52.5(0.015)$ & $38.8(0.015)$ & $53.4(0.015)$ & $47.3(0.009)$ \\
\hline $\begin{array}{l}\text { Percentage of respondents that believe it is acceptable to } \\
\text { discuss HIVIAIDS in newspaper }\end{array}$ & $96.8(0.006)$ & $95.8(0.007)$ & $97.4(0.005)$ & $96.6(0.003)$ \\
\hline $\begin{array}{l}\text { Percentage of respondents that believe it is acceptable to } \\
\text { discuss HIVIAIDS on TV }\end{array}$ & $98.7(0.004)$ & $96.4(0.006)$ & $98.5(0.004)$ & $97.7(0.003)$ \\
\hline $\begin{array}{l}\text { Percentage of respondents that believe it is acceptable to } \\
\text { discuss HIVIAIDS on radio }\end{array}$ & $98.4(0.004)$ & $96.5(0.006)$ & $98.3(0.004)$ & $97.6(0.003)$ \\
\hline
\end{tabular}

*Aggregated parameter estimates across States were calculated using weighted data 


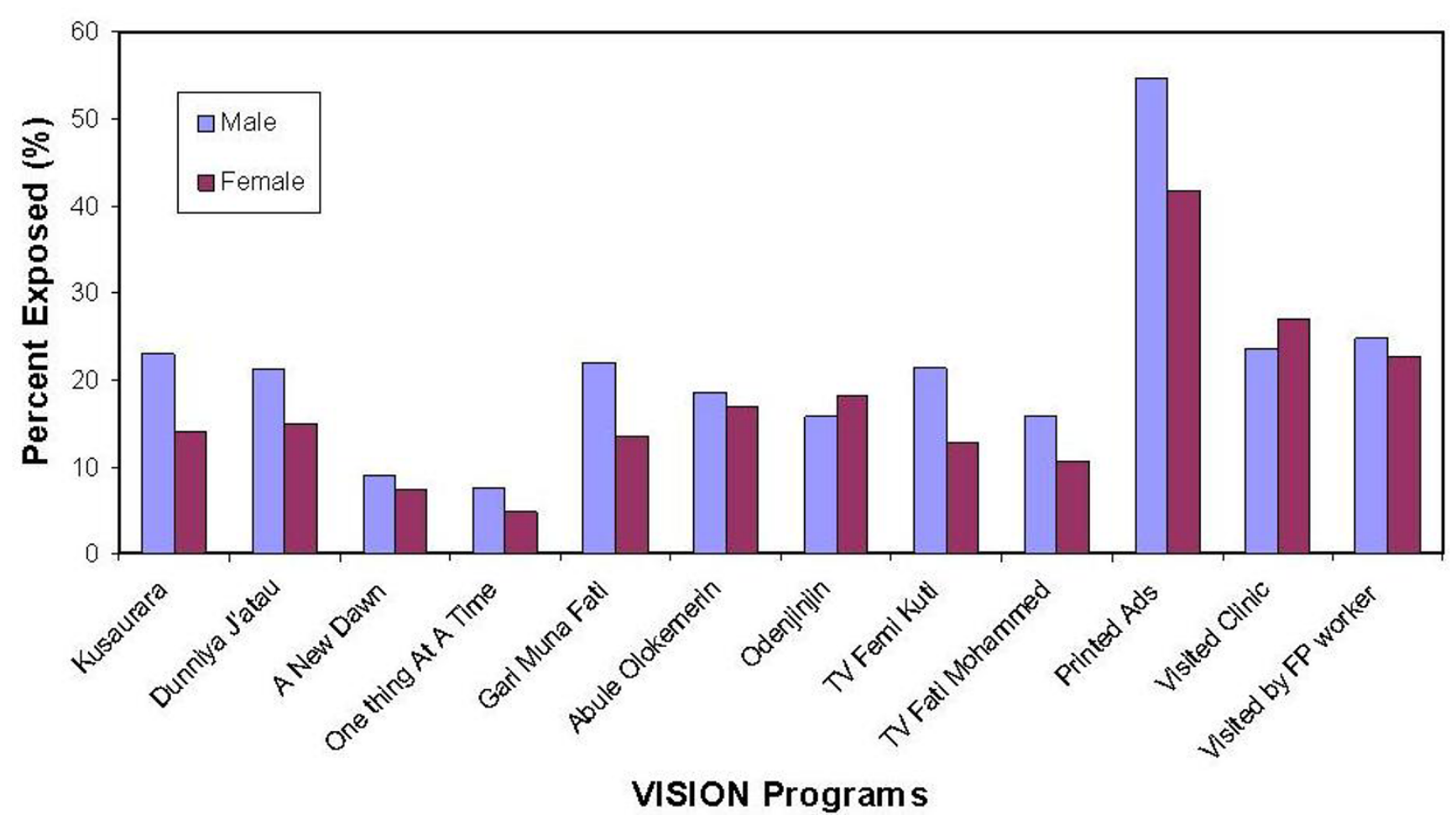

Figure I

VISION media program exposure Figure legend text - Percentage of respondents exposed to media programs implemented by the VISION project and its partners, by gender $(n=3,279)$

Table 3: Poisson regression results (beta coefficients) estimating exposure to the number of media programs over the past 6 months (3 models)

\begin{tabular}{|c|c|c|c|}
\hline Covariates $(\mathrm{PSU}=\mathrm{I} 20)$ & Total Programs $(n=3,249)$ & Radio ( $n=3,249$ ) & $\operatorname{TV}(n=3,252)$ \\
\hline Watch television once a week & $0.237^{* *}$ & 0.082 & $0.664 * *$ \\
\hline Listen to the radio once a week & $0.634^{* *}$ & $0.787^{* *}$ & $0.407^{*}$ \\
\hline Read newspaper once a week & $0.174 * *$ & $0.15 I^{*}$ & $0.296 *$ \\
\hline Age (continuous variable) & -0.002 & $-0.007 * *$ & $0.015^{* *}$ \\
\hline $\begin{array}{l}\text { At least I partner in past } 12 \\
\text { months }\end{array}$ & 0.039 & 0.033 & 0.013 \\
\hline \multicolumn{4}{|l|}{$\begin{array}{l}\text { Education (No formal education: } \\
\text { Reference) }\end{array}$} \\
\hline Primary & $0.139 *$ & 0.112 & 0.104 \\
\hline Secondary & $0.270 * *$ & $0.15 I^{*}$ & $0.257^{*}$ \\
\hline \multicolumn{4}{|l|}{ Residence (Rural: Reference) } \\
\hline Urban/peri-urban & $0.193 * *$ & 0.185 & $0.869 * *$ \\
\hline \multicolumn{4}{|l|}{ Gender (Female: Reference) } \\
\hline Male & $0.135^{* *}$ & $0.108^{*}$ & $0.185^{*}$ \\
\hline Married or living with partner & 0.013 & $0.104^{*}$ & $-0.289 * *$ \\
\hline \multicolumn{4}{|l|}{ State (Oyo: Reference) } \\
\hline Bauchi & $0.531 * *$ & $0.578 * *$ & $0.808^{* *}$ \\
\hline Enugu & -0.103 & $-0.264^{*}$ & -0.156 \\
\hline Constant & $-0.643 * *$ & $-0.958 * *$ & $-3.493 * *$ \\
\hline
\end{tabular}

$\S$ Weighted data were used for the Poisson regression; †Standard errors were estimated using a sandwich estimator; *Significant with $\mathrm{p}$-value $<0.05$; $* *$ Significant with $p$-value $<0.001$; Note: The values indicated in the table represent the estimated beta coefficients. A positive beta coefficient indicates a positive association with number of program exposures. The constant term represents the direction and magnitude of the relationship for the respective reference categories.

$=3.2, \mathrm{P}=0.07)$. The percentage of respondents that used 


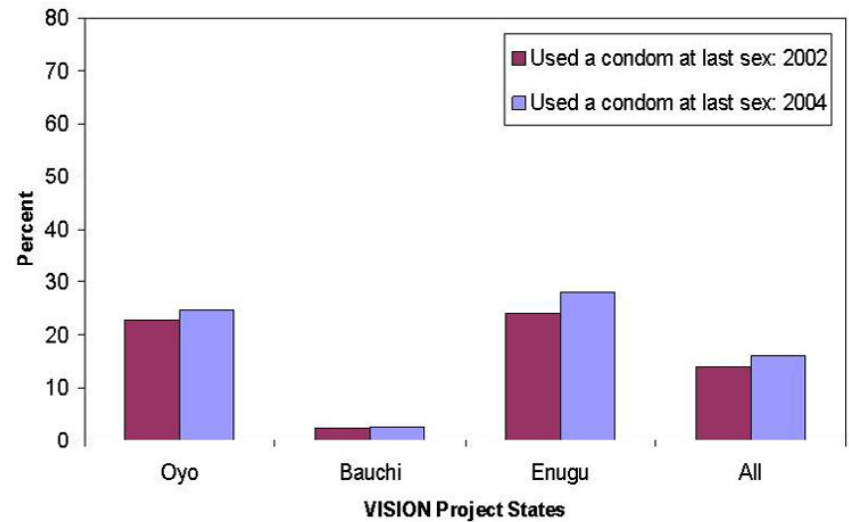

Figure 2

VISION outcome indicator in relation to 2002 baseline data: Condom use at last sex Figure legend text Percentage of respondents that used a condom at last sex: 2002 baseline and 2004 follow-up data. Aggregated estimates were calculated using weighted data

a condom at last sex was lowest in Bauchi and greatest in Enugu in both 2002 and 2004. The percentage of respondents that have discussed ways to prevent getting HIV/AIDS with a partner increased from $44.7 \%$ in 2002 to $48.1 \%$ in $2004\left(\chi^{2}=3.7, \mathrm{P}=0.05\right)$ (Figure 3 ). The percentage of respondents that have discussed ways to prevent getting HIV/AIDS with a partner was over 50\% for Enugu and Oyo in both 2002 and 2004. In Bauchi, the percent increased from $24 \%$ in 2002 to $38 \%$ in 2004 . The percentage of respondents that believe consistent condom use

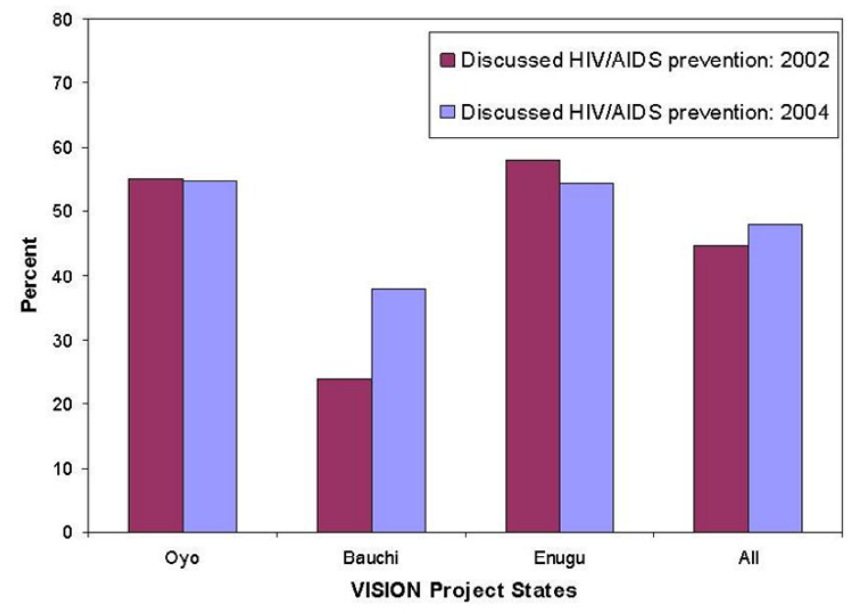

Figure 3

VISION outcome indicator in relation to 2002 baseline data: Discussed HIVIAIDS prevention Figure legend text - Percentage of respondents that have discussed ways to prevent getting HIVIAIDS with partner: 2002 baseline and 2004 follow-up data. Aggregated estimates were calculated using weighted data

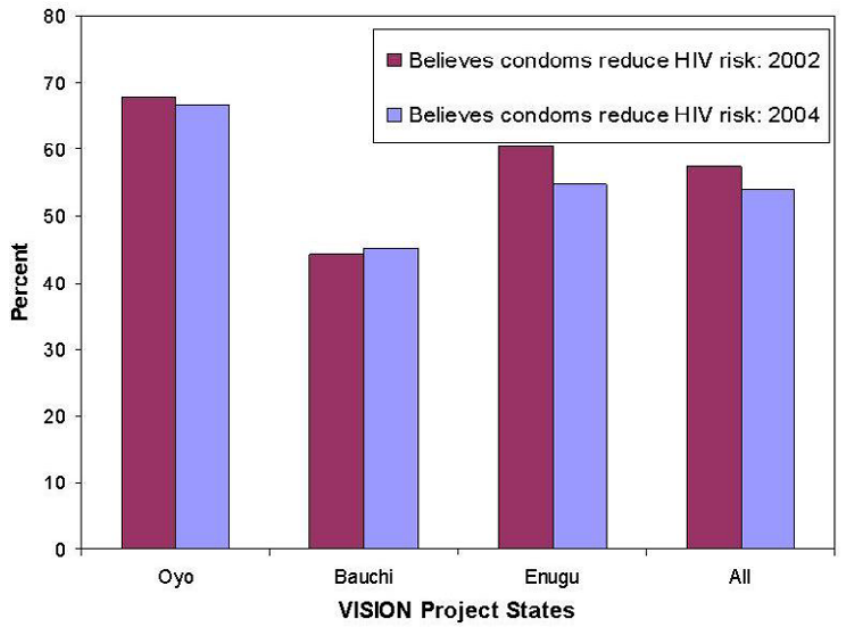

Figure 4

VISION outcome indicator in relation to 2002 baseline data: Condoms reduce HIV risk Figure legend text - Percentage of respondents that believe consistent condom use reduces risk of HIV infection: 2002 baseline and 2004 follow-up data. Aggregated estimates were calculated using weighted data

reduces risk of HIV infection was well over $40 \%$ in all 3 states for both survey rounds (Figure 4); overall, the percent decreased from $57 \%$ in 2002 to $54 \%$ in $2004\left(\chi^{2}=\right.$ $5.2, \mathrm{P}=0.02)$. This decrease largely stems from a reduction in perceived condom efficacy in Enugu.

The effect of exposure on the relative odds that respondents were willing to discuss HIV/AIDS with their partner is shown in Table 4 . Those with high program exposure were almost one and a half (O.R. $=1.47$, C.I. $1.01-2.16)$ times more likely than those with no exposure to have discussed HIV/AIDS with their partner, after controlling for the potential confounding effects of socio-demographic variables. The results for models testing the effect of individual programs (i.e. radio programs and TV programs) on the odds that respondents discussed HIV/AIDS with their partners were not significant. Strong positive associations were detected between education and the relative odds of the outcome occurring, as evidenced by highly significant odds ratios for both primary and secondary education categories for all models. Married respondents, or respondents reportedly living with a partner, where nearly two times more likely than unmarried respondents to have discussed HIV/AIDS [O.R. = 2.01 (C.I. 1.58-2.55), 1.98 (C.I. 1.55-2.51), 2.00 (C.I. 1.57-2.54) for models 1-3, respectively]. Lastly, there appears to be a strong positive association between those reporting that they know where to obtain condoms, and willingness to discuss HIV/AIDS with their partners $[\mathrm{OR}=2.83$ (C.I. 2.22-3.61), 2.84 (C.I. 
Table 4: Logistic regression results estimating relative odds that a sexually experienced respondent discussed HIVIAIDS with a partner

\begin{tabular}{|c|c|c|c|c|c|c|}
\hline \multirow[b]{3}{*}{ Covariates $(\mathrm{PSU}=\mathrm{I} 20)$} & \multicolumn{6}{|c|}{ Program Exposure (Adjusted Odds ratio: $n=2,504$ ) } \\
\hline & \multicolumn{2}{|c|}{ Total Exposure } & \multicolumn{2}{|c|}{ Radio exposure } & \multicolumn{2}{|c|}{ TV exposure } \\
\hline & 1 & $95 \%$ C.I. & 2 & $95 \%$ C.I. & 3 & $95 \%$ C.I. \\
\hline \multicolumn{7}{|c|}{ Total Program Exposure (Low: Reference) } \\
\hline Estimated High & $1.47^{*}$ & $1.01-2.16$ & & & & \\
\hline Estimated Medium & 1.12 & $0.86-1.47$ & & & & \\
\hline \multicolumn{7}{|c|}{ Radio Program Exposure (Low: Reference) } \\
\hline Estimated High & & & 1.16 & $0.66-2.05$ & & \\
\hline Estimated Medium & & & 1.27 & $0.97-1.66$ & & \\
\hline \multicolumn{7}{|l|}{ TV Program Exposure (Low: Reference) } \\
\hline Estimated High & & & & & N/A & \\
\hline Estimated Medium & & & & & 0.97 & $0.56-1.67$ \\
\hline Age (continuous variable) & $1.0 I^{*}$ & $1.01-1.03$ & $1.02 *$ & $1.01-1.03$ & $1.02 *$ & $1.01-1.03$ \\
\hline \multicolumn{7}{|l|}{ Education (No formal ed: Reference) } \\
\hline Primary & $1.56^{*}$ & $1.20-2.02$ & $1.66 * *$ & 1.28 & $1.70 * *$ & $1.30-2.24$ \\
\hline Secondary & $2.93 * *$ & $2.07-4.16$ & $3.25 * *$ & 2.16 & $3.43 * *$ & $2.42-4.84$ \\
\hline \multicolumn{7}{|l|}{ Residence (Rural: Reference) } \\
\hline Urban/peri-urban & 0.81 & $0.6 \mathrm{I}-\mathrm{I} .08$ & 0.90 & $0.69-1.17$ & 0.91 & $0.70-1.18$ \\
\hline \multicolumn{7}{|l|}{ Gender (Female: Reference) } \\
\hline Male & 1.09 & $0.88-1.35$ & 1.13 & $0.92-1.39$ & 1.16 & $0.95-1.42$ \\
\hline \multicolumn{7}{|l|}{ Religion (Catholic: Reference) } \\
\hline Protestant/other Christians & 1.09 & $0.80-1.48$ & 1.09 & $0.80-1.48$ & 1.09 & $0.80-1.48$ \\
\hline Muslim & 0.76 & $0.51-1.13$ & 0.76 & $0.5 \mathrm{I}-\mathrm{I} .14$ & 0.76 & $0.51-1.13$ \\
\hline Traditionalist & 0.62 & $0.28-1.38$ & 0.61 & $0.27-1.37$ & 0.62 & $0.27-1.39$ \\
\hline Knows where to get condoms & $2.83^{* * *}$ & $2.22-3.61$ & $2.84^{* *}$ & $2.23-3.62$ & $2.85^{* *}$ & $2.24-3.64$ \\
\hline Had at least I partner in past year & 1.12 & $0.97-1.32$ & 1.14 & $0.98-1.32$ & 1.15 & $0.98-1.33$ \\
\hline Married or living with partner & $2.01 * *$ & $1.58-2.55$ & $1.98 * *$ & $|.55-2.5|$ & $2.00 * *$ & $1.57-2.54$ \\
\hline \multicolumn{7}{|l|}{ State (Oyo: Reference) } \\
\hline Bauchi & 0.96 & $0.70-1.33$ & 0.99 & $0.68-1.44$ & 1.09 & $0.75-1.57$ \\
\hline Enugu & 1.08 & $0.77-1.51$ & 1.15 & $0.80-1.65$ & 1.04 & $0.75-1.45$ \\
\hline Pseudo-R ${ }^{2}$ & $12.8 \%$ & & $12.8 \%$ & & $12.7 \%$ & \\
\hline
\end{tabular}

$\S$ Weighted data were used for logistic regression models; †Standard errors were estimated using a sandwich estimator; *Significant with p-value < 0.05 ; **Significant with p-value $<0.00 \mathrm{I}$; Estimated High refers to 2 or more program exposures, Estimated Medium refers to greater than or equal to I program exposure but less than 2 program exposures, and Estimated low refers to less than I program exposure (reference), as estimated using Poisson regression at the ${ }^{\text {st }}$ stage of the analysis

2.23-3.62), 2.85 (C.I. 2.24-3.64) for models 1-3, respectively].

The effect of program exposure on the belief that consistent condom use can reduce the risk of HIV infection is shown in table 5 . Those with high program exposure were over twice (O.R. = 2.20, C.I. 1.49-3.25) as likely as those unexposed to know that consistent condom use can reduce risk of HIV infection. Those with moderate program exposure were almost 1 and a half $(O . R .=1.42$, C.I. 1.07-1.88) times more likely than those unexposed to know that condom use reduces risk of HIV infection. Model 2 indicates that exposure to at least 1 radio program is also significantly associated (O.R. $=1.33$, C.I. 1.02-1.73) with the odds of the outcome occurring, as compared to those not exposed to radio programs. Exposure to TV programs alone was not associated with the outcome. Also noteworthy is the strong significant association between secondary or higher education, and knowing that condoms reduce risk of HIV infection [O.R. $=1.49$ (C.I. 1.00-2.22), 1.85 (C.I. 1.27-2.70), 2.00 (C.I. 1.412.83) for models 1-3, respectively]. Those reporting knowledge of a condom source were almost four times more likely to also know that condoms can reduce the risk of HIV infection in all models. Those respondents located in Enugu were about half as likely as those in Oyo to know that condoms reduce risk of HIV.

The effect of exposure on condom use at last sexual intercourse is shown in table 6. Program exposure had no significant impact on reported condom use at last sex. Similarly, radio program exposure and TV program exposure had no significant effect. Male respondents were also more likely than female respondents to have reportedly 
Table 5: Logistic regression results estimating relative odds that a sexually experienced respondent knows that condom use reduces risk of HIV transmission

\begin{tabular}{|c|c|c|c|c|c|c|}
\hline \multirow[b]{3}{*}{ Covariates $(\mathrm{PSU}=120)$} & \multicolumn{6}{|c|}{ Program Exposure (Adjusted Odds ratio: $n=2,464$ ) } \\
\hline & \multicolumn{2}{|c|}{ Total Exposure } & \multicolumn{2}{|c|}{ Radio exposure } & \multicolumn{2}{|c|}{ TV exposure } \\
\hline & 1 & $95 \%$ C.I. & 2 & $95 \%$ C.I. & 3 & $95 \%$ C.I. \\
\hline \multicolumn{7}{|c|}{ Total Program Exposure (Low: Reference) } \\
\hline Estimated High & $2.20 * *$ & $1.49-3.25$ & & & & \\
\hline Estimated Medium & $1.42 *$ & $1.07-1.88$ & & & & \\
\hline \multicolumn{7}{|c|}{ Radio Program Exposure (Low: Reference) } \\
\hline Estimated High & & & 1.30 & $0.7 \mid-2.38$ & & \\
\hline Estimated Medium & & & $1.33^{*}$ & $1.02-1.73$ & & \\
\hline \multicolumn{7}{|l|}{ TV Program Exposure (Low: Reference) } \\
\hline Estimated High & & & & & $\mathrm{N} / \mathrm{A}$ & \\
\hline Estimated Medium & & & & & 0.91 & $0.52-1.63$ \\
\hline Age (continuous variable) & 0.99 & $0.99-1.01$ & 0.99 & $0.99-1.01$ & 1.00 & $0.99-1.01$ \\
\hline \multicolumn{7}{|l|}{ Education (No formal ed: Reference) } \\
\hline Primary & 1.03 & $0.75-1.42$ & 1.19 & $0.87-1.64$ & 1.23 & $0.90-1.69$ \\
\hline Secondary & $1.49 *$ & $1.00-2.22$ & $1.85 * *$ & $1.27-2.70$ & $2.00 * *$ & $1.4 \mid-2.83$ \\
\hline \multicolumn{7}{|l|}{ Residence (Rural: Reference) } \\
\hline Urban/peri-urban & 0.80 & $0.60-1.08$ & 0.97 & $0.73-1.30$ & 0.99 & $0.74-1.34$ \\
\hline \multicolumn{7}{|l|}{ Gender (Female: Reference) } \\
\hline Male & 0.93 & $0.76-1.13$ & 1.01 & $0.83-1.22$ & 1.04 & $0.86-1.26$ \\
\hline \multicolumn{7}{|l|}{ Religion (Catholic: Reference) } \\
\hline Protestant/other Christians & 0.78 & $0.58-1.06$ & 0.79 & $0.59-1.07$ & 0.79 & $0.58-1.07$ \\
\hline Muslim & 0.78 & $0.52-1.17$ & 0.79 & $0.52-1.19$ & 0.78 & $0.52-1.19$ \\
\hline Traditionalist & 1.23 & $0.53-2.86$ & 1.23 & $0.52-2.89$ & 1.22 & $0.52-2.88$ \\
\hline Knows where to get condoms & $3.72 * *$ & $3.00-4.68$ & $3.77 * *$ & $3.01-4.73$ & $3.8^{* *}$ & $3.03-4.77$ \\
\hline Had at least I partner in past year & 0.92 & $0.78-1.09$ & 0.94 & $0.80-1.10$ & 0.94 & $0.80-1.11$ \\
\hline Married or living with partner & 0.98 & $0.76-1.26$ & 0.96 & $0.75-1.24$ & 0.98 & $0.76-1.26$ \\
\hline \multicolumn{7}{|l|}{ State (Oyo: Reference) } \\
\hline Bauchi & $0.62 *$ & $0.45-0.86$ & $0.69 *$ & $0.48-0.98$ & 0.79 & $0.55-1.13$ \\
\hline Enugu & $0.59 *$ & $0.4 I-0.85$ & $0.62^{*}$ & $0.42-0.92$ & $0.55^{* *}$ & $0.38-0.79$ \\
\hline Pseudo- $R^{2}$ & $12.9 \%$ & & $12.5 \%$ & & $12.3 \%$ & \\
\hline
\end{tabular}

$\S$ Weighted data were used for logistic regression models; †Standard errors were estimated using a sandwich estimator; *Significant with $\mathrm{p}$-value < 0.05 ; **Significant with p-value $<0.00 \mathrm{I}$; Estimated High refers to 2 or more program exposures, Estimated Medium refers to greater than or equal to I program exposure but less than 2 program exposures, and Estimated low refers to less than I program exposure (reference), as estimated using Poisson regression at the $\left.\right|^{\text {st }}$ stage of the analysis

used a condom at last sex, for all program exposure models; those reporting knowledge of a condom source were approximately 9 times more likely than those without such knowledge to have used a condom at last sex for all program exposure models. Married respondents and respondents reportedly living with a partner were consistently less likely than the unmarried to have used a condom at last sex; those respondents located in Bauchi, were also less likely than those in the other two States to have used a condom at last sexual intercourse.

\section{Discussion}

Nigeria is one of several sub-Saharan African countries trying to deal with the current HIV/AIDS epidemic. In response to this need, the USAID-funded VISION Project launched a mass media campaign focusing on HIV/AIDS awareness, perception, and behavior modification. The purpose of this paper was to assess the determinants of program exposure, and test whether exposure to $\mathrm{FP} / \mathrm{RH} /$ HIV/AIDS program information translates into increased knowledge, awareness, and prevention of HIV/AIDS.

While the VISION project communication strategy predominantly focused on radio communications and community health workers, some of the VISION partners also used other media. The results from our study show that in combination these media activities had high reach among the target population. Exposure to radio communication was highest, with $59 \%$ of the population reporting to have heard at least one advertisement or radio program. Exposure to TV programs was the lowest media source, with $24 \%$ of the population reporting having seen at least one VISION program. Exposure to printed advertisements was also lower than radio program exposure, with approxi- 
Table 6: Logistic regression results estimating relative odds that a sexually experienced respondent used a condom at last sexual intercourse

Program Exposure (Adjusted Odds ratio: $n=2,099$ )

\begin{tabular}{|c|c|c|c|c|c|c|}
\hline \multirow[b]{2}{*}{ Covariates $(\mathrm{PSU}=\mathrm{I} 20)$} & \multicolumn{2}{|c|}{ Total Exposure } & \multicolumn{2}{|c|}{ Radio exposure } & \multicolumn{2}{|c|}{ TV exposure } \\
\hline & 1 & $95 \%$ C.I. & 2 & $95 \%$ C.I. & 3 & $95 \%$ C.I. \\
\hline \multicolumn{7}{|c|}{ Total Program Exposure (Low: Reference) } \\
\hline Estimated High & 1.40 & $0.68-2.89$ & & & & \\
\hline Estimated Medium & 0.95 & $0.57-1.61$ & & & & \\
\hline \multicolumn{7}{|c|}{ Radio Program Exposure (Low: Reference) } \\
\hline Estimated High & & & 1.73 & $0.53-5.66$ & & \\
\hline Estimated Medium & & & 1.42 & $0.76-2.66$ & & \\
\hline \multicolumn{7}{|c|}{ TV Program Exposure (Low: Reference) } \\
\hline Estimated High & & & & & N/A & \\
\hline Estimated Medium & & & & & 2.79 & $0.96-8.06$ \\
\hline Age (continuous variable) & 0.99 & $0.97-1.02$ & 0.99 & $0.97-1.02$ & 0.99 & $0.96-1.01$ \\
\hline \multicolumn{7}{|l|}{ Education (No formal ed: Reference) } \\
\hline Primary & 1.51 & $0.76-3.01$ & 1.47 & $0.73-2.99$ & 1.44 & $0.73-2.87$ \\
\hline Secondary & 1.58 & $0.74-3.37$ & 1.57 & $0.71-3.52$ & 1.56 & $0.78-3.11$ \\
\hline \multicolumn{7}{|l|}{ Residence (Rural: Reference) } \\
\hline Urban/peri-urban & 1.41 & $0.88-2.25$ & $1.58 *$ & $1.03-2.43$ & 1.57 & $1.02-2.43$ \\
\hline \multicolumn{7}{|l|}{ Gender (Female: Reference) } \\
\hline Male & $1.68^{*}$ & $1.22-2.32$ & $1.72 * *$ & $1.27-2.32$ & 1.79 & $1.34-2.40$ \\
\hline \multicolumn{7}{|l|}{ Religion (Catholic: Reference) } \\
\hline Protestant/other Christians & 0.87 & $0.57-1.32$ & 0.88 & $0.59-1.33$ & 0.90 & $0.59-1.35$ \\
\hline Muslim & $0.5 I^{*}$ & $0.27-0.96$ & $0.53^{*}$ & $0.28-0.99$ & $0.53^{*}$ & $0.29-0.98$ \\
\hline Traditionalist & 0.47 & $0.11-1.93$ & 0.46 & $0.11-1.89$ & 0.47 & $0.11-1.95$ \\
\hline Knows where to get condoms & $9.55^{* *}$ & $5.25-17.36$ & $9.58 * *$ & $5.32-17.26$ & $9.7 I^{* * *}$ & $5.37-17.56$ \\
\hline Had at least I partner in past year & 0.99 & $0.73-1.35$ & 1.00 & $0.74-1.37$ & 1.01 & $0.74-1.38$ \\
\hline Married or living with partner & $0.14 * *$ & $0.10-0.20$ & $0.14 * *$ & $0.09-0.20$ & $0.15^{* *}$ & $0.10-0.21$ \\
\hline \multicolumn{7}{|l|}{ State (Oyo: Reference) } \\
\hline Bauchi & $0.25 * *$ & $0.11-0.56$ & $0.23 * *$ & $0.08-0.66$ & $0.18^{*}$ & $0.07-0.47$ \\
\hline Enugu & 0.91 & $0.54-1.56$ & 1.09 & $0.56-2.08$ & 0.88 & $0.53-1.45$ \\
\hline Pseudo- $\mathrm{R}^{2}$ & $44.4 \%$ & & $44.4 \%$ & & $44.5 \%$ & \\
\hline
\end{tabular}

$\S$ Weighted data were used for logistic regression models; †Standard errors were estimated using a sandwich estimator; *Significant with $\mathrm{p}$-value < 0.05 ; **Significant with p-value $<0.00$ I; Estimated High refers to 2 or more program exposures, Estimated Medium refers to greater than or equal to I program exposure but less than 2 program exposures, and Estimated low refers to less than I program exposure (reference), as estimated using Poisson regression at the ${ }^{\text {st }}$ stage of the analysis

mately $47 \%$ having seen an advertisement about reproductive health or HIV/AIDS. Community health workers and visits to the clinic were also important information venues, with over $25 \%$ of the population having been exposed to one or the other.

Despite the relatively high percentage of respondents that believe consistent condom use can reduce the risk of HIV infection, and the high percentage of respondents that have discussed HIV/AIDS with a partner, relatively low numbers of respondents reported using a condom at last sex $(<16 \%)$. This result is consistent with other surveys done in Nigeria and suggests that different strategies for reaching subgroups within the population may be needed to increase condom use. Programs that specifically target rural populations, females, and unmarried individuals, as well as disseminate information on where to obtain con- doms, are needed to increase condom use in the VISION Project areas. The overall differences between the 2002 baseline data and the 2004 follow-up data in the three outcome indicators are small, suggesting that more needs to be done to increase HIV/AIDS awareness and influence behaviour change. However, the differentials by subgroups of the population suggest that changes are starting to occur among smaller subgroups within the population. This is consistent with theories of behaviour change that posit that some subgroups may have a more advanced stage of readiness for behaviour change. It is therefore important to investigate if exposure to media campaign is facilitating behaviour change.

Also of significance is the detected association between education and HIV/AIDS awareness and perceptions about the use of condoms for reducing the risk of HIV 
transmission, and the lack of detected significance between education and condom use. In all models of this analysis, those knowing where to obtain condoms was positively associated with increased HIV awareness and perception, and the use of condoms. These important outcomes lend insight into how and where future programs should be developed and implemented. Paramount to effecting behaviour change is the development of programs that create educational opportunities to enhance awareness, as well as the development of programs that create awareness about where condoms can be found. Concerted efforts must be made to reach populations that do not readily access media sources, or that are incapable of reading important public health announcements to disseminate information on the importance of using condoms consistently to reduce the risk of HIV transmission. This conclusion is further supported by results that suggest a majority of the community believes it is O.K. to discuss HIV/AIDS on the television and radio. Future efforts should also focus on increasing awareness of, and access to, condoms within the community.

As with any data collection and evaluation exercise, there exists limitations in both the data and study design that may distort the true effect of the program on the outcomes investigated. The VISION Project was designed as a fullcoverage program; as such, it was not possible to evaluate the effect of the program in relation to an equivalent comparison group. That is, we were unable to find a control group that would not be exposed to the intervention; because many of the partner NGOs were also active outside of the VISION Project target areas, contamination of the control areas was unavoidable. Hence, we decided on the use of a post-test design, and statistical techniques, to control for the potential limiting effects of extraneous variables in the analysis. That being said, in the absence of additional evidence, readers should be cautious when trying to generalize these results to other, and possibly dissimilar, areas.

There is evidence to suggest that program exposure is increasing the communities' willingness to discuss HIV/ AIDS with partners, as well as increasing the communities' knowledge about the benefits of consistent use of condoms for reducing HIV/AIDS risk. Less clear however, is the effect of the respective programs on condom use, as evidenced by insignificant estimated values, and differences in the magnitude of the effect between models. One possible explanation is that it may take much longer for the radio and TV programs to effect condom use behaviour change within the community. As state above, a second possibility is that our study design failed to capture the true effect, as a quasi-experimental design with a comparison group is better than a post-test design for teasing out the controlled effects of program exposure on behav- iour-related outcomes. In either case, this analysis suggests that a necessary next step is to specifically target groups within the population that are not currently aware of the dangers of HIV/AIDS, or not aware of the availability and location of prevention methods, and then scale up the coverage, content, and distribution of media campaigns in these populations to ensure that HIV/AIDS prevention information is readily available and understandable to the majority of the population.

\section{Conclusion}

The data shows that the FP/RH media campaign by VISION and its partners is reaching a large portion of the target population, and exposure to these mass media programs can help increase HIV/AIDS awareness. Programs that target rural populations, females, and unmarried individuals, as well as disseminate information on where to obtain condoms, are needed to reduce barriers to condom use. Although the overall differences in the outcome variables between 2002 baseline data and 2004 follow-up data were small, differences in the outcome variables observed in the respective project areas for sub-groups of the population suggest that change is starting to occur. Improvements in HIV/AIDS prevention behaviour are likely to require that these programmatic efforts be continued, scaled up, done in conjunction with other interventions, and targeted towards individuals or areas with specific socio-demographic characteristics.

\section{Competing interests}

The author(s) declare that they have no competing interests.

\section{Authors' contributions}

JK analyzed and interpreted the data, and drafted the manuscript. DM designed the study, assisted with the analysis and interpretation of data, and drafted sections of the manuscript. AA led data collection activities, designed the study, and provided substantial content for subsequent revisions to the manuscript. All authors read and approved the final manuscript.

\section{Acknowledgements}

This study was funded by the United States Agency for International Development (USAID) through the MEASURE Evaluation Project and under the terms of Cooperative Agreement GPO-A-00-03-00003-00. The authors are grateful to Beth Nauman for her assistance with the literature review, and to Susan Kano and Toyin Akpan for comments and suggestions on an earlier draft. The authors are also grateful to the staff and trainers at CRERD for their data collection efforts. We also thank two reviewers for their helpful comments and suggestions for improving the manuscript.

\section{References}

I. UNAIDS and the World Health Organization: Epidemiological fact sheet on HIVIAIDS and sexually transmitted infections: Nigeria (revised). Geneva 2002. 2000 
2. UNAIDS and the World Health Organization: Epidemiological fact sheet on HIVIAIDS and sexually transmitted infections: Nigeria (revised). Geneva 2004.

3. National Population Commission (NPC) [Nigeria] and ORC Macro: Nigeria Demographic and Health Survey 2003 Calverton, Maryland; 2004.

4. Temin MJ, Okonofua FE, Omorodion FO, Renne EP, Coplan P, Heggenhougen HK, Kaufman J: Perceptions of sexual behaviour and knowledge about sexually transmitted diseases among adolescents in Benin City, Nigeria. International Family Planning Perspectives 1999, 25(4): 186-190.

5. Van Rossem R, Meekers D, Akinyemi Z: Consistent Condom Use with Different Types of Partners: Evidence from Two Nigerian Surveys. AIDS Education and Prevention 200I, I3(3):252-267.

6. Araoye MO, Fakeye OO, Jolayemi ET: Contraceptive method choices among adolescents in a Nigerian tertiary institution. West African Journal of Medicine 1998, I 7(4):227-23 I.

7. Jinadu MK, Odesanmi WO: Adolescent sexual behaviour and condom use in Ife-Ife, Nigeria. Clinical Nursing Research 1993 , 2(I): III-II8

8. Odujinrin OMT, Akinkuade FO: Adolescents AIDS knowledge, attitudes and beliefs about preventive practices in Nigeria. European Journal of Epidemiology 1991, 7(2): I 27-I33.

9. Agha S, Escudero G, Keating J, Meekers D: Nigeria (Bauchi, Enugu and Oyo) Family Planning and Reproductive Health Survey 2002. Health Facility Survey Results. MEASURE Evaluation Technical Report Series, No. I6B Carolina Population Center, UNC; 2003.

10. Agha S, Escudero G, Keating J, Meekers D: Nigeria (Bauchi, Enugu and Oyo) Family Planning and Reproductive Health Survey. MEASURE Evaluation Technical Report Series, No. 16 Chapel Hill, Carolina Population Center, UNC; 2002.

II. VISION Project: Annual Report October I, 2002-September 30, 2003. Lagos 2003.

12. VISION Project: Quarterly Report October-December Lagos 2003.

13. VISION Project: Public-Private Partnerships for Increased Service Use, End-of-Project Report. Lagos .

14. Meekers D, Van Rossem R, Zellner S, Berg R: Using Behavior Change Communications to Overcome Social Marketing Sales Plateaus. Case Studies of Nigeria and India. Commercial Market Strategies, Technical Paper Series No.7 Washington, D.C., Commercial Market Strategies.

15. Bollen K, Guilkey D, Mroz T: Binary outcomes and endogenous explanatory variables: Tests and solutions with applications to the demand for contraceptive use in Tunesia. Demography 1995, 32(1):|II-|3|.

16. Davidson R, MacKinnon J: Estimation and Inference in Econometrics New York, Oxford University Press; 1993.

\section{Pre-publication history}

The pre-publication history for this paper can be accessed here:

http://www.biomedcentral.com/1471-2458/6/123/pre pub
Publish with Biomed Central and every scientist can read your work free of charge

"BioMed Central will be the most significant development for disseminating the results of biomedical research in our lifetime. "

Sir Paul Nurse, Cancer Research UK

Your research papers will be:

- available free of charge to the entire biomedical community

- peer reviewed and published immediately upon acceptance

- cited in PubMed and archived on PubMed Central

- yours - you keep the copyright
BioMedcentral 